\title{
CHARACTERIZATION OF BAMBOO BASED CARBON POWDER APPLICABLE FOR FABRICATION OF LOW-COST COUNTER ELECTRODES OF DYE-SENSITIZED SOLAR CELLS
}

\author{
Prakash Joshi*
}

\begin{abstract}
Low-cost carbon powder prepared by carbonization of bamboo wood was characterized by means of X-rays diffraction (XRD) and Raman spectroscopy. The structural analysis of the carbon powder shows that the material is the composite of amorphous and graphitic forms of carbon. Furthermore, the carbon powder was used as the counter electrode material of dye-sensitized solar cell (DSC) and the electric property of the bamboo carbon based counter electrode was investigated by obtaining current-voltage (I-V) curve of the DSC.
\end{abstract}

Key words: Bamboo, carbon powder, counter electrode, dye-sensitized solar cell, platinum.

\section{INTRODUCTION AND OBJECTIVE}

The electricity generated from solar cells is gaining popularity among energy consumers these days (Paudel et al., 2012). Solar cells based on silicon wafers are dominant solar cells in the global energy market (Gratzel, 2005). However, dye-sensitized solar cells (DSCs) based on nano-crystalline titanium dioxide $\left(\mathrm{TiO}_{2}\right)$ have been attracting researchers throughout the world because of their low-fabrication cost compared with the silicon based solar cells (Joshi, et al., 2009, O'Reganand \& Gratzel, 1991, Paudel et al., 2012).

A DSC comprises two electrodes called photoelectrode (photoanode) and counter electrode. Basically, the photoelectrode consists of a thin film of nano-crystalline $\mathrm{TiO}_{2}$ particles coated on fluorine doped tinoxide (FTO)-glass substrate and the $\mathrm{TiO}_{2}$ particles are coated with light sensitive dye molecules. Generally, the counter electrode (CE) is a FTOglass substrate with a thin film of platinum. The two electrodes are separated by a spacer and the gap between them is filled with an electrolyte. The electrolyte is a system of chemicals dissolved in a solvent and it (electrolyte)

* Mr. Joshi is an Associate Professor, Bhaktapur Campus, Bhaktapur, TU. 
contains iodide ( $\left.\mathrm{I}^{-}\right)$and tri-iodide $\left(\mathrm{I}_{3}^{-}\right)$ions. When the photoelectrode of a DSC is exposed to light (diffused sunlight or direct sunlight or both), the incident light photons eject electrons from the dye molecules. The photoelectron reaches to the counter electrode after travelling through a load. The iodide ions in the electrolyte give electrons to the oxidized dye molecules and they (dye molecules) are re-generated, but the iodide ions are converted to tri-iodide ions after they lose the electrons. The tri-iodide ions receive the photo-electrons arrivedat the CEand they (tri-iodide ions) turn into iodide ions, the platinum film (of the $\mathrm{CE}$ ) accelerates the reduction of tri-iodide ions into iodide ions (Gratzel, 2005, Joshi, et al., 2009, Joshi, et al., 2010, O'Reganand \& Gratzel, 1991, Paudel et al., 2012).

Platinum is the most preferred catalyst used in DSCs (Joshi, et al., 2009, Paudel et al., 2012).However, it has disadvantages: it is a high cost metal and it is unstable in corrosive electrolyte (Joshi, et al., 2009, Olsen, et al., 2012). Carbon has been preferred as an alternative counter electrode material (catalyst) and various types of carbon have been adopted as the catalyst for tri-iodide reduction in DSCs (Joshi, et al., 2009, Joshi, et al., 2010, Joshi, et al., 2012, Joshi, 2017, Paudel et al., 2012). Among the carbon based counter electrode materials, the plant-based carbon can be a low-cost catalyst for tri-iodide reduction in DSCs and the activated carbon of Lapsi (Choerospondias axillaris)-seed stone and Utis (Alnus nepalensis) plant-wood have been used as the catalyst (Joshi, 2017). However, the efficiencies of the DSCs withthe plant based carbon were not significantly high. Thus, there exists a need to search for a plant based efficient carbon as a counter electrode material.

In this article, the carbon powder was prepared by carbonization of chemically activated powder of bamboo wood aiming to use the carbon as a low-cost and efficient counter electrode material of DSCs. The nature of materials used in the fabrication of counter electrodes can influence photovoltaic performance of the DSCs. The materials with good catalytic activity for the reduction of tri-iodide ions and high electric conductivity (or low resistivity) are recommended for preparing efficient counter electrodes of DSCs (Poudel and Qiaon, 2013). In this regards, applicability of the bamboo based carbon for fabrication of counter electrode of the DSC was evaluated by performing structural analysis of the carbonaceous material using the techniques of XRD and Raman spectroscopy. Furthermore, electric series resistance of a DSC can also affect photovoltaic performance of the device, higher value of series resistance of solar cell reduces squareness (fillfactor) of the current-voltage (I-V) curve of the device (Joshi, et al., 2010). Thus, 
the applicability of the bamboo based carbon as counter electrode material has also been evaluated by comparing the current-voltage (I-V) curve of the DSCwith CE based on the carbon powder and the I-V curve of the DSC with $\mathrm{CE}$ based on platinum.

\section{MATERIALS AND METHOD}

The carbon powder of bamboo was prepared following similar method described by Joshi (2017). First of all, bamboo (locally known as Dhanu Bans) was collected from the bamboo shrubsat Jhaukhel area of Bhaktapur (Fig1a). The bamboo was cut into small pieces with a knife (Fig. 1b). The samples were washed with distilled water and dried in an oven. Then, the pieces of the bamboo were turned into powder using a steel file (Fig 1c). The powder was filtered and the fine powder of the bamboo was chemically activated with phosphoric acid. In order to obtain the carbon powder, the chemically activated sample was carbonized in nitrogen atmosphere at $\sim 400^{\circ} \mathrm{C}$ using a tubular furnace. Fig. $1 \mathrm{~d}$ shows the carbon powder (activated carbon) of the bamboo wood. X-ray diffraction of the carbon powder was carried out using the powder diffractometer available at Nepal Academy of Science and Technology (NAST), Nepal. Similarly, Raman spectroscopy of the carbon film prepared with the carbon powder was carried out using the Raman spectrometer of RI Instrument and Innovative India.

Figure 1: a) Bamboo shrubs, b) pieces of bamboo, c) bamboo wood powder, and d) carbon powder of bamboo wood.

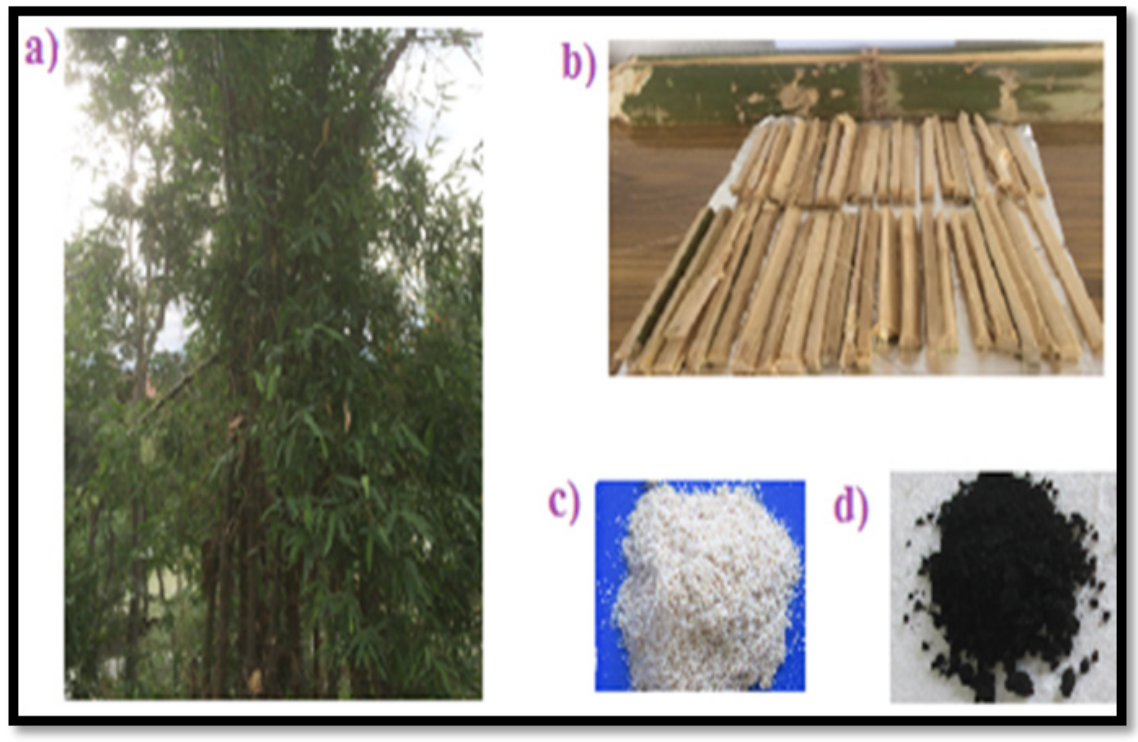


Fig. 2: a) Cell structure of DSC with CE based on carbon film of bamboo, b) photograph of a typical DSC with CE prepared from carbonaceous material (carbon film).

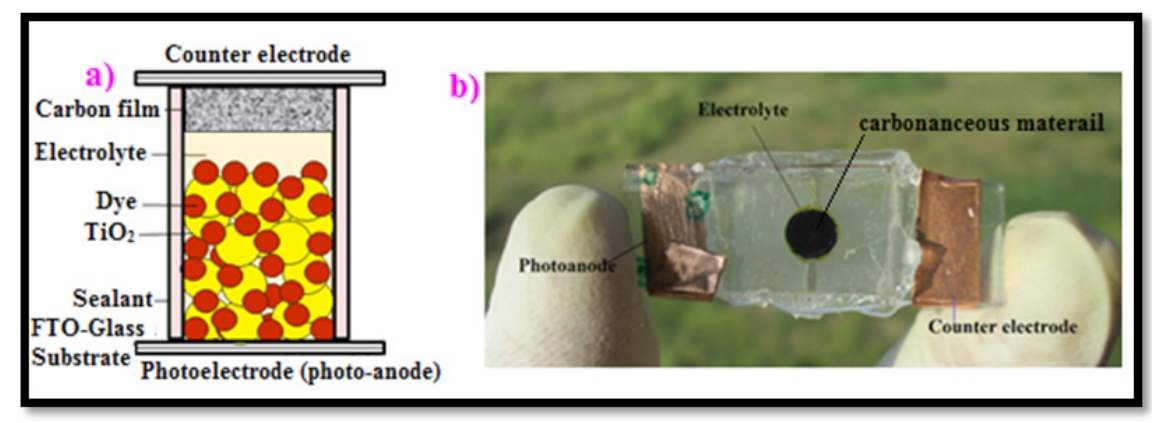

The bamboo based carbon powder was used for making counter electrodes of DSCs. Also, the counter electrodes and DSCs were fabricated following similar experimental procedures described by Joshi (2017). First of all, the paste of the carbon powder was prepared with an organic binder in distilled water and the paste was doctor-bladed onto FTO-glass substrates (Hartford Glass, USA). Finally, the FTO-glass substrates with the doctorbladed carbon paste were sintered using a hot-plate and the FTOs with the sintered film of the carbon paste were used as CEs for the DSCs. The photo-electrodes of the DSCs were prepared by doctor-blading $\mathrm{TiO}_{2}$ paste (Ti-Nanoxide T/SP, Solaronix, Switzerland) onto the FTO-glass substrates and sintering the substrates with the doctor-bladed paste. The transparent film of sintered $\mathrm{TiO}_{2}$ nano-particles was sensitized with N-719 dye which was purchased from Solaronix. The dye-sensitized photoelectrodes were assembled with the carbon based counter electrodes by means of para-film sheets. Finally, liquid electrolyte (purchased from Solaronix) was injected into the gap between the two electrodes. Fig. 2a is a schematic diagram of a DSC with carbon film as CE material and Fig. $2 b$ is the photograph of a typical DSC with CE prepared from carbonaceous material (carbon film). Also, DSCs with platinum as counter electrodes were fabricated. The platinum based DSCs have similar photoelectrodes and electrolyte as the carbon based cells. Both the carbon based solar cells and platinum based solar cells were tested in natural sunlight without masks usinga home-built instrument and their I-V curves were obtained following similar experimental set up and procedures reported by Joshi (Joshi, 2017). 
Figure 3: Structural characterization of carbonaceous material prepared from carbonization of bamboo wood: a) XRD, b) Raman spectra.
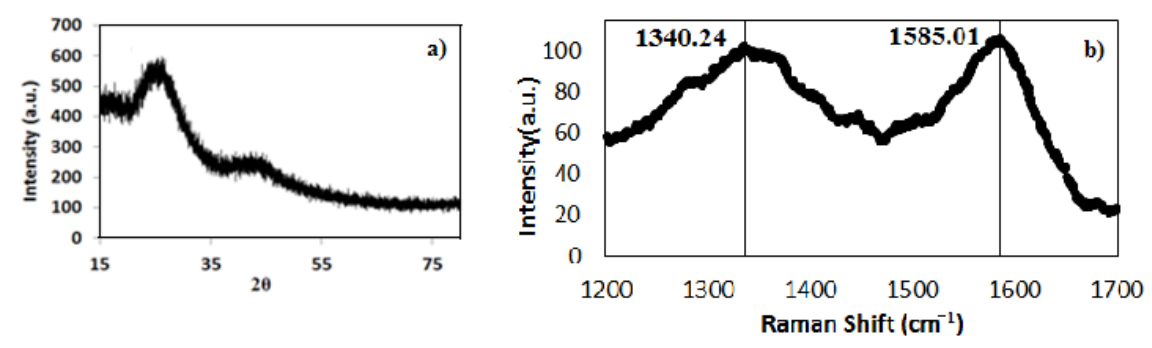

Figure 4: Scanning electron microscope (SEM) image of the film prepared from carbon powder of bamboo. The image was taken by using the SEM (JSM-6301F) available at the department of physics in Brooklyn College, the City University of New York, USA.

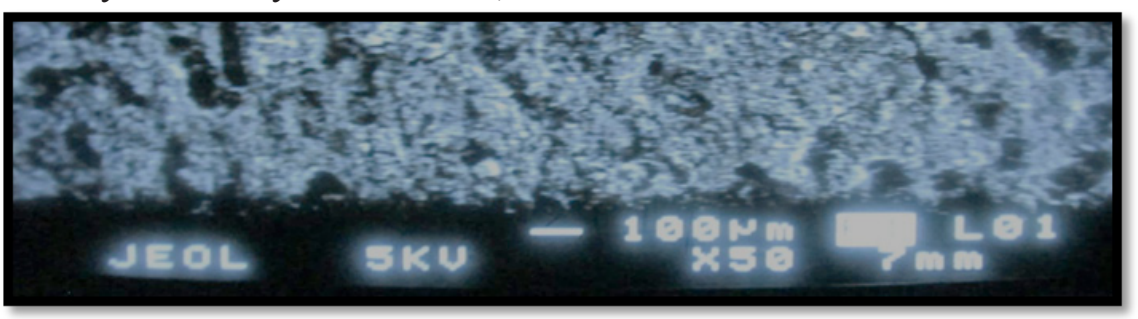

Figure 5: Current-Voltage curves of a) dye-sensitized solar cell with carbon of bamboo wood tested in natural sunlight of $13.41 \mathrm{mw} / \mathrm{cm}^{2}, \mathrm{~b}$ ) dyesensitized solar cell with platinum tested in natural sunlight of $15.50 \mathrm{mw} /$ $\mathrm{cm}^{2}$. The active area of each cell was $\sim 0.066 \mathrm{~cm}^{2}$.

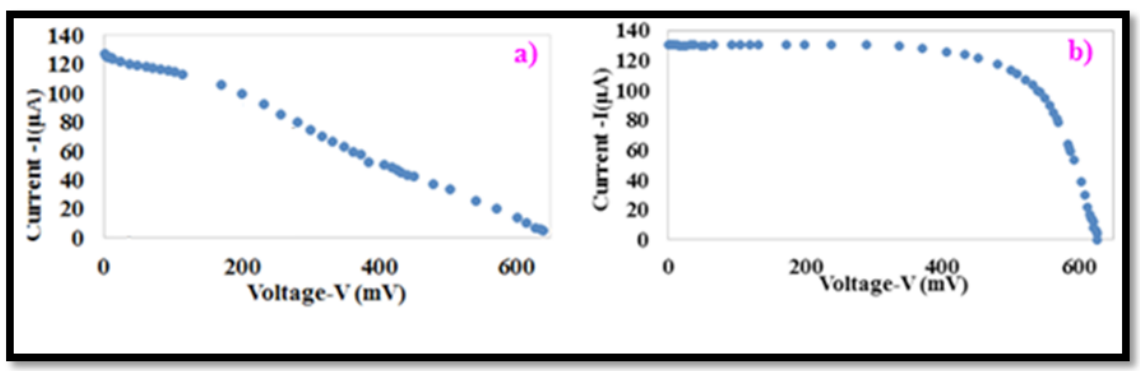

\section{RESULT AND DISCUSSION}

The X-ray diffraction (XRD) of the carbon powder prepared from bamboo is shown in Fig.3a. The X-ray diffraction pattern of the material shows a peak at $2 \theta \approx 25^{\circ}$ and such peak arises due to the diffraction of X-rays 
from the material with the carbon of graphitic structure (Joshi, et al., 2010, Joshi, 2017). Fig. 3b is the Raman spectra of the carbon film prepared with the carbon powder. The peak around wave number $\sim 1585 \mathrm{~cm}^{-1}$ (G-mode) is attributed to the graphitic carbon (ordered carbon). Additionally, the peak around wave number $\sim 1340 \mathrm{~cm}^{-1}$ (D-mode) is related to amorphous carbon or disordered carbon (Joshi, et al., 2010, Joshi, et al., 2012, Joshi, et al., 2017). While reporting the photovoltaic performance of electro-spun nano fibers, Joshi et al.(2012) have reported that carbonaceous material containing graphitic form of carbon and dis-ordered (amorphous) carbon can be an efficient catalyst as platinum for the reduction of tri-iodide ions. Hence, the carbon powder of bamboo can also be a catalyst for the reduction of tri-iodide ions in DSCs.

Fig. 4 is the screenshot of the scanning electron microscope (SEM) image of the carbon film prepared with the carbon powder. The SEM image reveals that the film consists of carbon flakes whose size ranges from a few micrometers to tens of micrometers. Moreover, the carbon film has rough and porous surface. The rough surface of the film ensures high surface area, the film with high surface area provides a large electrolyte-catalyst (carbon) interface. Similarly, the micron-sized pores in the film provide easy access to the liquid electrolyte for deep penetration inside the film. Thus, the rough and porous surface morphology can facilitate fast reduction of the tri-iodide ions (Poudel and Qiao, 2013).

Fig.5a depicts I-V curve of the DSC with CE coated with the bamboo based carbon. Fig. $5 \mathrm{~b}$ is the I-V curve of the DSC with the CE coated with platinum. The squareness of the I-V curve of bamboo carbon based solarcell was less than the squareness of the I-V curve of platinum based cell. This indicates that FF factor of the bamboo based DSC is smaller than that of the platinum based DSC. The calculated values of the FF of bamboo based DSC and platinum based DSC were $\sim 0.29$ and $\sim 0.72$, respectively. Previous researchers have reported that the lower value of FF of carbon based solar cells is attributed to higher value of series resistance $\left(R_{s}\right)$ of the device (Joshi, et al., 2010, Murakami, et al., 2006). As the FF of the bamboo carbon based DSC was much smaller than that of the platinum based DSC, the $\mathrm{R}_{\mathrm{s}}$ of the bamboo carbon based DSC can be significantly larger than of the platinum based DSC.The value of $\mathrm{R}_{\mathrm{s}}$ of DSCs under illumination can be estimated by the value of the reciprocal of the slope of the tangent drawn at the point on the I-V curve where the value of current (I) is zero (Schroder, 2005). The values of $R_{s}$ calculated from the $I-V$ curves of bamboo (Fig. 5a) 
and platinum (Fig. 5b) were $\sim 268.71 \Omega-\mathrm{cm}^{2}$ and $19.14 \Omega-\mathrm{cm}^{2}$, respectively. The $\mathrm{R}_{\mathrm{s}}$ of the DSC based on the carbon powder of bamboo is much larger than that of the DSC with platinum based counter electrode. Moreover, higher value of $\mathrm{R}_{\mathrm{s}}$ of the carbon based DSC can be understood as follow. The two types of the solar cells have identical photo-electrodes and liquid electrolyte, hence, the resistance contributed from these two components of the cells to the total value of $\mathrm{R}_{\mathrm{s}}$ of the solar cells should be nearly equal. This indicates that the resistance contributed to the $\mathrm{R}_{\mathrm{s}}$ by the $\mathrm{CE}$ of the carbon based DSC should be larger than that contributed by the CE of platinum based DSC. Generally, counter electrode material with high resistivity can cause high value of $\mathrm{R}_{\mathrm{s}}$. Hence, the resistivity of carbon film (prepared from the bamboo based carbon powder) of CE of the carbon based DSC might be much higher than that of the thin film of platinum coated on $\mathrm{CE}$ of the platinum based DSC. However, I-V curves of the two types of solar cells show comparable short circuit current $\left(\mathrm{I}_{\mathrm{sc}}\right)$ and open circuit voltage $\left(\mathrm{V}_{\mathrm{oc}}\right)$. This implies that carbon film prepared from bamboo based carbon powder possesses catalytic ability for the reduction of tri-iodide ions in DSCs.

\section{CONCLUSION}

Carbon powder was prepared by simple method of carbonization of bamboo wood. Structural characterization of the carbon powder and photovoltaic parameters of the DSCs based on the carbon powder confirm that material could be used as a catalyst for the reduction of tri-iodide ions in dye sensitized solar cells.

\section{ACKNOWLEDGEMENTS}

The author is very thankful to NAST. Similarly, the author is grateful to Prof. Dr. Armila Rajbhandari (Nyachhon), Central Department of Chemistry, Tribhuvan University (T.U.) and Ms. Dibya Shree Shrestha, Patan Multiple Campus, T.U. for their contributions in preparation of the carbon powder of bamboo wood. The author is also thankful to RI Instrument and Innovative India for running Raman spectroscopy of the sample, Brooklyn College, the City University, USA for SEM imaging, Kathmandu University for making necessary arrangement for the Raman spectroscopy, Bhaktapur Campus, T.U. for providing research facilities.

\section{REFERENCES}

Gratzel, M., (2005). Solar energy conversion by dye-sensitized photovoltaic cells. Inorg. Chem., 44, 6841-6851. 
Joshi, P., Xie, Y., Ropp, M., Galipeau, D., Bailey, S., and Qiao, Q., (2009). Dye-sensitized solar cells based on low cost nanoscale carbon/tio ${ }_{2}$ composite counter electrode. Energy Environ. Sci., 2, 426-429.

Joshi, P., Zhang, L., Chen, Q., Galipeau, Q., Fong, H., and Quan, Q., (2010). Electrospun Carbon Nanofibers as low-cost counter Electrode for Dye-sensitized solar cells. Acs Applied Materials \& Interfaces, 2, 3572-3577.

Joshi, P., Zhou, Z., Poudel, P., Thapa, A., We, X.-F., and Qiao, Q., (2012). Nickel incorporated carbon nanotube/nanofiber composites as counter electrodes for dye-sensitized solar cells. Nanoscale, 4, 5659-5664.

Joshi, P., (2017). Novel counter electrodes of dye-sensitized solar cells based on activated carbon prepared from wood of Choerospondias axillaris seed-stones and Alnus nepalensis plant. International Journal of Engineering and Advanced Research Technology (IJEART), 3, 8-11.

Murakami,T.N., Ito, S., Wang, Q.,Nazeeruddin, Md. K.., Bessho, T., Cesar, I., Liska,P., HumphryBaker, R., Comte, P., Péchy, P., and Grätzel, M., (2006). Highly efficient dye-sensitized solar cells based on carbon black counter electrodes. J. of Electrochemical Society, 153, A2255-A226.

O'Regan, B., \& Gratzel, M., (1991). A low-cost, high-efficiency solar-cell based on dye-sensitized colloidal $\mathrm{TiO}_{2}$ films. Nature,353, 737740 .

Olsen, E.,Hagen, G., \& Lindquist, S.E., (2012). Dissolution of platinum in methoxy propionitrile containing LiI/ $\mathrm{I}_{2}$. Solar Energy Materials \& Solar Cells, 63, 267-273.

Paudel, P., Zhang, L., Joshi, P., Venkatesan, S., Fang, H., and Quan, Q. (2012). Enhanced performance in dye-sensitized solar cells via carbon nanofibers-platinum composite counter electrodes. Nanoscale, 4, 4726-4730.

Poudel, P., and Qiaon, Q., (2013). Carbon nanostructure counter electrodes for low cost and stable dye-sensitized solar cells. Nano Energy, 4, $157-175$.

Schroder, D. K. (2005). Semiconductormaterial and devicecharacterization. Wiley Interscience. 